\title{
Marine seismic surveys and ocean noise: time for coordinated and prudent planning
}

\author{
Douglas P Nowacek ${ }^{1,2^{*}}$, Christopher W Clark ${ }^{3}$, David Mann ${ }^{4}$, Patrick JO Miller ${ }^{5}$, Howard C Rosenbaum ${ }^{6}$,
} Jay S Golden ${ }^{7}$, Michael Jasny ${ }^{8}$, James Kraska ${ }^{1}$, and Brandon L Southall ${ }^{1,9}$

\begin{abstract}
Marine seismic surveys use intense (eg $\geq 230$ decibel [dB] root mean square [RMS]) sound impulses to explore the ocean bottom for hydrocarbon deposits, conduct geophysical research, and establish resource claims under the United Nations Convention on the Law of the Sea. The expansion of seismic surveys necessitates greater regional and international dialogue, partnerships, and planning to manage potential environmental risks. Data indicate several reasons for concern about the negative impacts of anthropogenic noise on numerous marine species, including habitat displacement, disruption of biologically important behaviors, masking of communication signals, chronic stress, and potential auditory damage. The sound impulses from seismic surveys - spanning temporal and spatial scales broader than those typically considered in environmental assessments - may have acute, cumulative, and chronic effects on marine organisms. Given the international and transboundary nature of noise from marine seismic surveys, we suggest the creation of an international regulatory instrument, potentially an annex to the existing International Convention on the Prevention of Pollution from Ships, to address the issue.
\end{abstract}

Front Ecol Environ 2015; 13(7): 378-386, doi:10.1890/130286

$\mathrm{T}$ he time has come to improve international coordination among industries, governments, scientists, and environmental organizations in understanding and managing the risks that marine seismic surveys can pose to individual animals, populations, and ecosystems. Marine seismic surveys represent a major contributor to ocean noise in terms of overall energy and spatiotemporal ranges of influence; other important contributors include commercial

\section{In a nutshell:}

- Marine seismic surveys produce intense sound impulses to explore the ocean floor for energy sources and for research purposes

- Environmental reviews of seismic surveys are seldom undertaken at scales necessary to meaningfully assess, mitigate, and monitor their impacts; managing exposure of marine animals to these sounds requires additional attention and data

- Current exposure threshold criteria fail to account for the best available science and the cumulative effects of simultaneous seismic surveys and prolonged, repeated exposures

- Increasing marine seismic surveys, especially in ecologically sensitive areas, require multi-institutional and international collaboration to effectively manage risks

- We propose that anthropogenic ocean noise be addressed through the revision of the existing MARPOL Convention or negotiation of a new convention that more comprehensively evaluates the associated risks, benefits, and procedures

${ }^{1}$ Nicholas School of the Environment, Duke University Marine Laboratory, Beaufort, NC *(dpn3@duke.edu); ${ }^{2}$ Pratt School of Engineering, Duke University, Durham, NC; ${ }^{3}$ Bioacoustics Research Program, Cornell Lab of Ornithology, Cornell University, Ithaca, NY; ${ }^{4}$ Humu Labs, Cambridge, MA; continued on p 386 shipping (Hildebrand 2009). Technological improvements and economic market forces in petroleum and natural gas exploration have extended the spatial and temporal reach of seismic surveys, notably into higher latitudes and deeper waters, during most months of the year. This not only increases the potential total area for development, but in some regions (eg the Mediterranean and northeastern North Atlantic) also raises issues regarding overlapping jurisdiction and governance. Recently, enabled in part by declines in sea ice, seismic exploration has expanded rapidly into many parts of the Arctic. This has motivated countries bordering the Arctic Ocean to gain exclusive access to seabed resources by claiming sovereign rights over the extended continental shelf, under Part VI of the United Nations (UN) Convention on the Law of the Sea (UNCLOS 1982). These developments, coupled with the demand for hydrocarbon resources, are key drivers of the expansion of seismic surveys worldwide. Although the market forces governing this expansion are ephemeral, these commercial and political activities are generally occurring at ever-larger scales and extending into previously unexplored areas. An integrated program for monitoring, mitigating, and reporting would facilitate development of a knowledge-based understanding of potential risks and solutions; the establishment of such a program would necessitate coordination and prudent planning.

Efforts to monitor the undersea acoustic environment and manage the impacts of noise generated by human activities have reached a critical juncture. The European Union (EU) has recognized ocean noise as an indicator of environmental quality under its Marine Strategy Framework Directive (EU 2008) and is in the process of developing targets for achieving "good environmental 

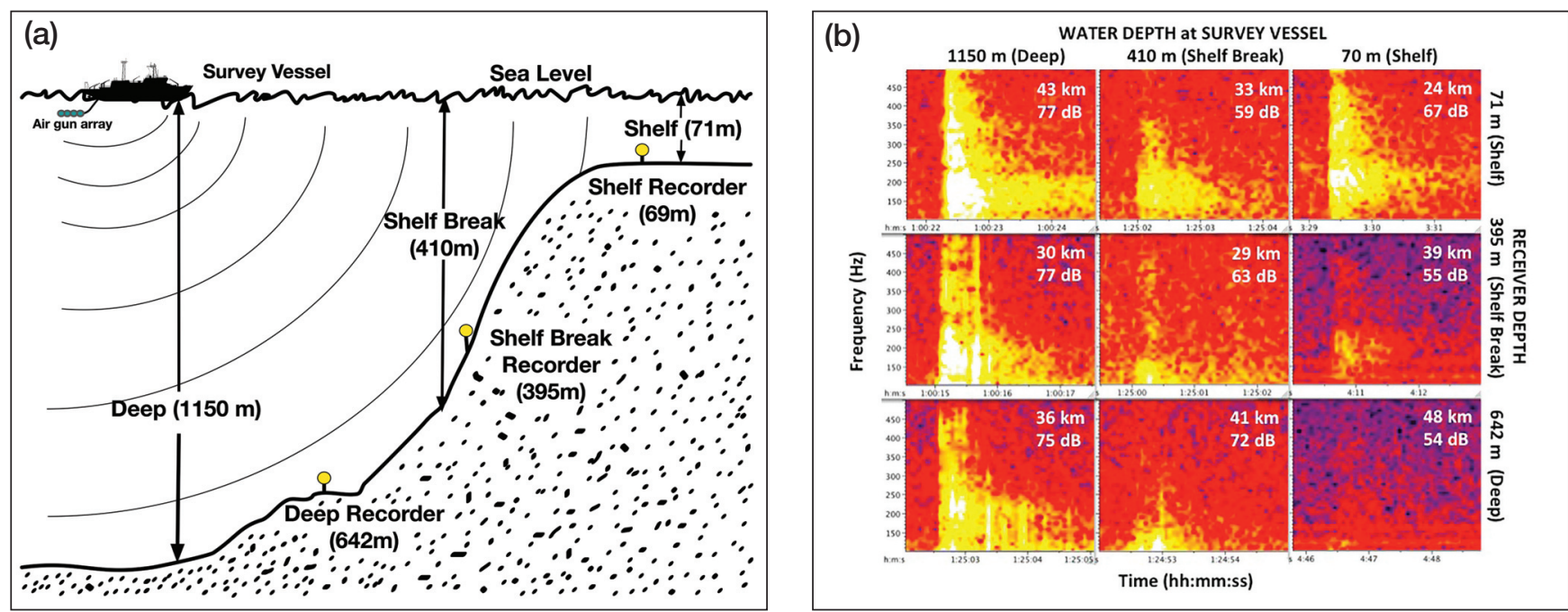

Figure 1. (a) Depiction of a marine seismic survey occurring in deep water. The diagram shows a seismic survey vessel relative to acoustic recorders (data from these recorders are shown in [b]), which are deployed $2 \mathrm{~m}$ above the seafloor at three water depths: deep $(642 \mathrm{~m})$, shelf break $(395 \mathrm{~m})$, and shelf $(69 \mathrm{~m})$. The seismic airgun array is towed at $\sim 10-\mathrm{m}$ depth off the stern. In this case, the seismic vessel is operating over deep water $(1150 \mathrm{~m})$, and later operating over the shelf break $(410 \mathrm{~m})$ and shelf $(71 \mathrm{~m})$ areas. Note that the data samples shown in (b) are from sounds from the vessel operating at all three water depths, but seismic signals were recorded at each recording station when the ship operated at every depth. (b) Spectrograms (each representing higher relative intensity as brighter color with time on the $x$ axis and frequency on the $y$ axis) illustrating seismic impulses as received by recorders at three depths (rows) when the seismic survey vessel was operating at three water depths (columns). The three water depths and the three recorder depths for each of the nine examples are given in $(a)$. The distance $(\mathrm{km})$ from the source (vessel) to the receiver (recorder) and the received levels ( $\mathrm{dB}$ re: $1 \mu \mathrm{Pa}^{2}$-sec) for each impulse are given in the upper right corner of each spectrogram. In the examples shown here, when the source is operating in deep water $(1150 \mathrm{~m})$, the higher received level $(77 \mathrm{~dB})$ occurs at the shallowest receiver ( $69 \mathrm{~m}$; row 1, column 1) at the longest range (43 km). In contrast, when the source is operating in shallow water (71 $\mathrm{m})$, the lowest received level (54 dB) occurs at the deepest receiver (642 $\mathrm{m}$; row 3, column 3) at the longest range $(48 \mathrm{~km})$.

status" for ocean noise and acute noise-producing activities; moreover, in 2014, the EU identified seismic-survey noise as a factor in the preparation of environmental impact assessments (EIAs; EU 2014). Similarly, the US recognizes underwater noise in the preparation of EIAs for oil and gas development in regions under its jurisdiction, particularly the Gulf of Mexico, the Atlantic Ocean, and the Arctic Ocean (eg BOEM 2014, a and b). These efforts, which are still under development, are indicative of the stage and scale of actions required to address these critical issues.

Advances in integrated monitoring, assessment, and planning are essential for nations in the early phases of offshore hydrocarbon exploration, such as Greenland (administered by Denmark), which is presently assembling its initial regulatory structure with regard to seismic surveys. An integrated approach requires increasing both the breadth and depth of baseline data on the demographic trends and overall health of marine animal populations, as well as analyzing the cumulative effects of exposure to multiple noise sources and the potential interactions between those sources and other anthropogenic stressors. These analyses must be conducted on appropriate temporal and spatial scales, which may span jurisdictional boundaries or extend beyond national legislation. Under certain conditions, seismic survey signals can be detected at great distances - in one instance,
$4000 \mathrm{~km}$ - from their respective sources (Nieukirk et al. 2004, 2012). While the specific effects of such signals on marine species at these ranges are not known, current monitoring, assessment, and mitigation approaches fail to consider both the spatiotemporal extent of the acoustic phenomena and the potential impacts even at moderate ranges $(10-100 \mathrm{~km})$, distances through which acoustic energy from the pulses can propagate efficiently (Figure 1). Notably, the survey from which the data in Figure 1 were acquired occurred in Arctic waters, where the sound velocity profile favors a surface duct [Urick 1983], thus resulting in the retention of energy near the surface and efficient propagation of energy onto the shelf when the source vessel is operating over deep water. These observations contrast with those reported by Nieukirk et al. [2012], in which conditions favored downward propagation such that energy from sources in shallow and shelf-break waters propagated very efficiently to deep-water recorders located thousands of kilometers away). An integrated approach to assessment must be coupled with appropriate mitigation that focuses on the acoustic ecology of marine animals and the minimization of cumulative acoustic exposures (Rio Declaration 1992).

Here, we offer perspectives on the management of seismic operations and the mitigation of the accompanying risks. 


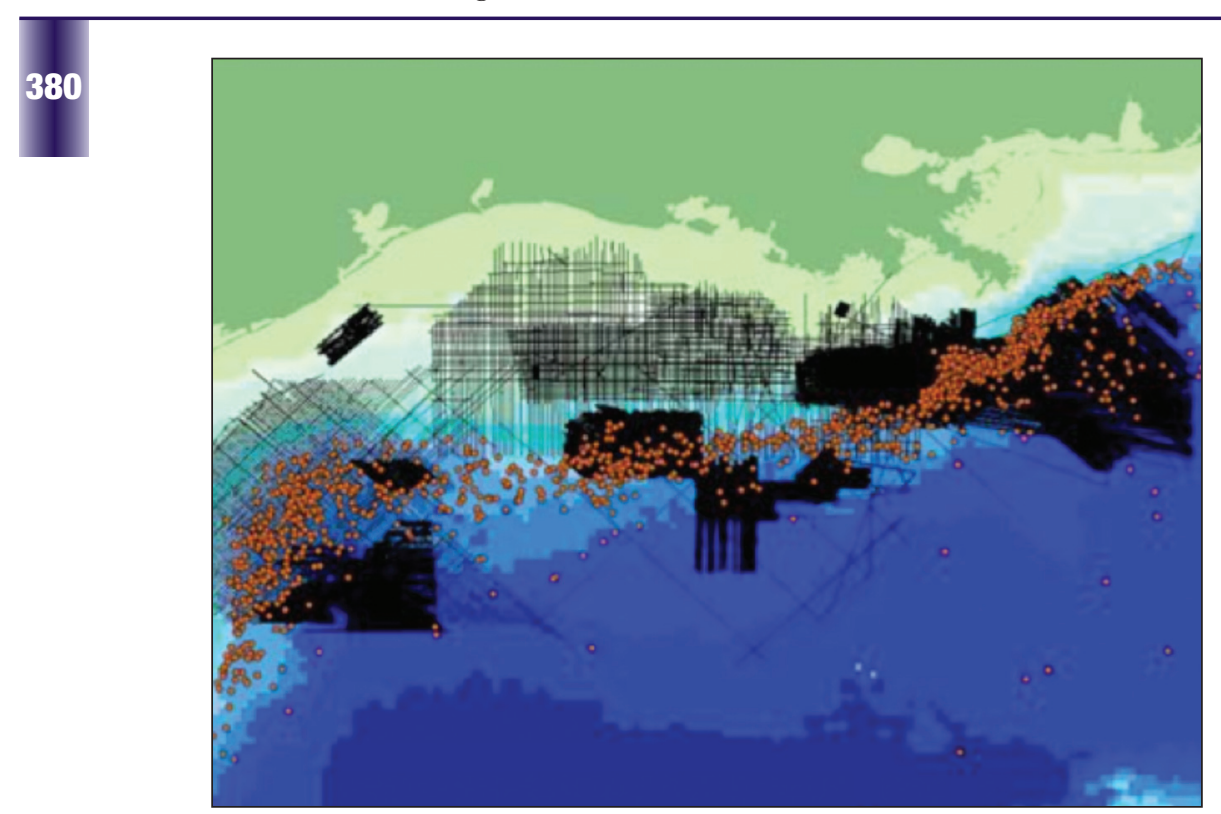

Figure 2. Overlap of seismic surveys and sperm whale (Physeter macrocephalus) locations in the Gulf of Mexico. The black lines and blotches are seismic survey tracklines reported by the International Association of Geophysical Contractors (IAGC) for the period from July 2002 to October 2006. Red dots are locations of sperm whales during the same period, as determined by satellite-linked tags attached to individual whales. Blue colors in the background indicate depth contours, with the darkest blue being the 2000-m contour, the next lighter shade being the 1000-m contour, and so on. From Jochens et al. (2008).

\section{Appropriate impact thresholds}

The potential impacts of seismic surveys, as with other anthropogenic noise sources, are typically assessed as the results of individual activities (eg a single survey) through relatively simple methods based entirely on expected sound exposure levels and decades-old guidelines (HESS Team 1999). Impact is evaluated on the estimated number of animals subjected to a sound level high enough to possibly cause harm or disturbance. While sound-exposure levels are clearly important for individual animals over the short spatial and temporal scales generally analyzed, recent documentation of the areas affected by seismic signals indicates that a broader paradigm of assessment is required (Guerra et al. 2011; Nieukirk et al. 2012). Given the ubiquity of seismic surveys in some areas (Figure 2) and the potential for impacts in the large areas currently being opened for resource exploration (Figure 3), we are concerned about the simplicity, artificial rigidity, and increasingly outdated nature of impact thresholds and the methods used to quantify the potential impacts of discrete activities in environmental assessments and rulemaking. To explore this subject further and to elaborate on related issues (eg masking [Clark and Ellison 2004; Clark et al. 2009; Hatch et al. 2012], stress [Warner and Heimstra 1971; Evans 2003; Otten et al. 2004; Wright et al. 2007], and behavioral responses [Castellote et al. 2012]), we provide additional information in WebPanel 1 and Table 1.
To move beyond the currently applied acuteimpact thresholds and to capture a more realistic metric for the potential impacts of seismic surveys and other marine noise-generating activities, regulatory agencies should implement an analytical function to provide a probabilistic assessment of impact severity. Such a function should incorporate the spatial and temporal dynamics and spectral characteristics of the acoustic field generated by the specific activity (eg a seismic survey), as well as account for the aggregate sound field resulting from multiple anthropogenic activities, industrial or otherwise.

\section{- Increasing the breadth and depth of baseline data}

The fact that insufficient data existed for many Gulf of Mexico species prior to the 2010 Deepwater Horizon disaster - because of inadequate sampling - indicates a broad failure on the part of federal resource-management agencies in the US. This failure limits scientists' ability not only to assess the true impacts of the Gulf disaster in retrospect but also to anticipate and plan for future prevention and remediation. Unfortunately, this lack of baseline biological data is not unique to the Gulf of Mexico. Indeed, many places around the world where considerable seismic exploration is ongoing or is projected to occur, suffer from similar, or worse, baseline data shortfalls. For most cetacean populations, numerical abundance and trends in abundance are the standard measurements for assessing population status, but such measurements are difficult to obtain and have limitations (eg require decades of research and are complicated by resolution of temporal trends; see Taylor et al. 2007). It should therefore be a priority to develop additional metrics for population health (eg Harwood et al. 2011), such as measures of vital rates, distribution, ranging patterns, population structure, and body condition. Where possible, such information should be collected in areas where seismic activities are planned or ongoing, and existing data should be used to the maximum extent possible. Next, a reasonable understanding of the ecosystem is needed, as changes in prey availability and distribution can also drive changes in predator populations and distributions. Obtaining such data is especially critical, as climate-driven changes may be altering community structure and function (eg Grebmeier et al. 2006).

Without sufficient baseline data, we believe it is unrealistic for regulators to reach scientifically reliable conclusions about the risks to marine life from marine seismic surveys. The process for permitting surveys must take these data needs into account and be adjusted accordingly, and perhaps even paused while such information is gathered. 


\section{Cumulative effects}

Assessing the impact of seismic surveys has typically been limited to individual environmental assessments that often focus only the loudest sound source (eg seismic airgun arrays) and for a single survey. This ignores sub-bottom profilers, support vessels, undersea communication systems, shipping vessels, and other major sources of noise that must be quantitatively analyzed in combination with airgun surveys to comprehensively estimate the potential impacts on marine life (eg Southall et al. 2013). Given our rapidly improving understanding of the spatial, temporal, and spectral scales of the acoustic footprints generated by these seismic activities, this single-source regulatory approach is no longer appropriate. In some countries, national legislation - such as Australia's Environment Protection and Biodiversity Conservation Act, Canada's Species at Risk Act, and the US's Marine Mammal Protection Act and Endangered Species Act - make regulators responsible for ensuring that activities have minimal impacts on marine populations, particularly those of threatened or endangered species, and for prescribing mitigation strategies that would reduce impacts to the lowest possible level. Regulators are failing to meet their statutory obligations if the cumulative exposure to and potentially interacting influences of the full suite of anthropogenic activities occurring in the same region are being inadequately evaluated.

We acknowledge the practical challenges involved in trying to understand and manage interacting and/or cumulative impacts (eg limitations in quantifying impacts, regulatory governance within borders that are largely artificial given the transboundary nature of sound propagation, animal movements). However, it is essential that standards be applied programmatically and internationally to include all seismic exploration and associated anthropogenic activities that could potentially affect marine species or populations thereof, and we propose a structure for such application below. For migratory and resident marine animals, particularly those with limited dispersal abilities, the potential for disturbance from cumulative impacts is high. Migratory baleen whales, for example, are likely to encounter seismic surveys in many parts of their home ranges, including feeding and breeding grounds and the migration routes between them (eg Rosenbaum et al. 2014). Furthermore, seismic activities need to be managed programmatically and through multi-year processes, rather than through separate harassment authorizations, as has been the standard procedure in the US. Recent steps toward that end, including the recent Draft Environmental Impact Statement for industrial development in the US Arctic (NMFS 2013), are encouraging, at least in that cumulative and potentially interacting effects are considered. Specifically in the case of Arctic development, though the National Marine Fisheries Service identified and described the problem, the agency neglected to propose an explicit process for analyzing or accounting for its cumulative impacts. This is clearly a challenging management task, and some tangible efforts and measures - using a risk assessment paradigm, for instance - are sorely needed.

The relative value of individual habitats (eg feeding, breeding, migratory) should be considered, and repeat exposures of animals that display a strong fidelity to a particular habitat should be part of cumulative effects analyses. The sustained presence of animals in an area under development is an insufficient indicator of the absence of adverse impacts, particularly given the challenges of detecting population trends (Taylor et al. 2007). Some animals may have limited abilities to move elsewhere, and their decision to remain in an area may likely reflect tolerance (ie persisting in an important area despite the cost) rather than habituation (Bejder et al. 2009). Indeed, recent studies on seismic-survey impacts have documented responses such as declines in prey capture signals, a proxy for foraging success, in cetaceans that have not abandoned the affected portions of their home ranges (eg 


\begin{tabular}{|c|c|c|c|c|}
\hline Species & Location & Response/effect & Received level & Reference(s) \\
\hline $\begin{array}{l}\text { Bowhead whale } \\
\text { (Balaena mysticetus) }\end{array}$ & Arctic & $\begin{array}{l}\text { Change in } \\
\text { surface respiration; avoidance; } \\
\text { call cessation }\end{array}$ & $\begin{array}{l}\text { I20-I30 dB re: I } \mu \mathrm{Pa} R M S \\
\text { II6-I29 dB re: I } \mu \mathrm{Pa} R M S\end{array}$ & $\begin{array}{l}\text { Richardson et al. (1999); } \\
\text { Robertson et al. (20I3); } \\
\text { Blackwell et al. (20I3) }\end{array}$ \\
\hline $\begin{array}{l}\text { Sperm whale } \\
\text { (Physeter macrocephalus) }\end{array}$ & Gulf of Mexico & $\begin{array}{l}\text { Buzz (feeding) rate } \\
\text { decline }\end{array}$ & I35-I47 dB re: I $\mu \mathrm{Pa}$ RMS & Miller et al. (2009) \\
\hline $\begin{array}{l}\text { Harbor porpoise } \\
\text { (Phocoena phocoena) }\end{array}$ & North Sea & $\begin{array}{l}\text { Temporary displacement; } \\
\text { buzz (feeding) rate decline }\end{array}$ & $\begin{array}{l}\text { |45-I5| dB re: I } \mu \mathrm{Pa}^{2}-\mathrm{sec} \\
\text { I30-I65 dB re: I } \mu \mathrm{Pa}^{2}-\mathrm{sec}\end{array}$ & $\begin{array}{l}\text { Thompson et al. (20|3); } \\
\text { Pirotta et al. (20|4) }\end{array}$ \\
\hline $\begin{array}{l}\text { Beluga whale } \\
\text { (Delphinapterus leucas) }\end{array}$ & Arctic & Temporary displacement & $\sim 130 \mathrm{~dB}$ re: I $\mu \mathrm{Pa}$ RMS & Miller et al. (2005) \\
\hline $\begin{array}{l}\text { Humpback whale } \\
\text { (Megaptera novaeangliae) }\end{array}$ & Angola & Singing and singers declined & I20-I50 dB re: I $\mu \mathrm{Pa}$ peak & Cerchio et al. (2014) \\
\hline $\begin{array}{l}\text { Fin whale } \\
\text { (Balaenoptera physalus) }\end{array}$ & Mediterranean & $\begin{array}{l}\text { Altered singing and } \\
\text { abandonment of habitat }\end{array}$ & $\begin{array}{l}\sim 15 \mathrm{~dB} I \mu \mathrm{Pa} \text { above } \\
\text { background }\end{array}$ & Castellote et al. (20I2) \\
\hline $\begin{array}{l}\text { Fish (herring, blue whiting } \\
\text { [Micromesistius poutassou]) }\end{array}$ & Norway & $\begin{array}{l}\text { Displacement, horizontal } \\
\text { and vertical }\end{array}$ & $\begin{array}{l}\text { Unknown, occurred over } \\
\text { large study area }\end{array}$ & Slotte et al. (2004) \\
\hline $\begin{array}{l}\text { Fish (cod, pollock } \\
\text { [Pollachius spp]) }\end{array}$ & UK (Scotland) & $\begin{array}{l}\text { Short-term startle, } \\
\text { no long-term effects }\end{array}$ & Variable & Wardle et al. (200I) \\
\hline $\begin{array}{l}\text { Fish (pink snapper } \\
\text { [Pagrus auratus]) }\end{array}$ & Captive & Hearing system damage & $\begin{array}{l}\text { Variable I50-180 dB } \\
\text { re: I } \mu \mathrm{Pa} \text { RMS }\end{array}$ & McCauley et al. (2003) \\
\hline
\end{tabular}

Notes: This is not intended to be a complete compilation, only a sample showing representative species, geographic locations, and documented responses/effects. Ongoing studies (eg Cato et al. $201 \mathrm{I}$ ) should provide additional information about effects of seismic surveys. $\mathrm{dB}=\mathrm{decibel} ; \mu \mathrm{Pa}=$ micropascal; $\mathrm{RMS}=$ root mean square.

Miller et al. 2009; Pirotta et al. 2014). The cumulative, synergistic, and chronic effects of elevated noise levels, including those from "intermittent" sounds such as seismic airguns and sounds at relatively low received levels (eg Figure 1), are detrimental in humans and other mammals, affecting hormone systems as well as behavior (eg Warner and Heimstra 1971; Evans 2003; Otten et al. 2004; Wright et al. 2007). These effects of elevated noise levels should be an explicit component of environmental impact statements and rulemakings, rather than being vaguely acknowledged but not substantively addressed.

\section{A responsible way forward}

Given the transboundary scale and numerous sources of anthropogenic sound in the world's oceans - including noise from marine seismic surveys, which are ubiquitous and increasing in abundance - we believe that a responsible path forward should focus on the creation of legally binding international commitments.

Successful precedents exist for crafting such agreements, including the Cartagena Protocol on Biosafety (CPD 2000; UNSCBD 2000) organized under the Convention for Biological Diversity (CBD 1992) and the Convention on Long-range Transboundary Air Pollution (CLRTAP 1979). The CLRTAP was the first international legally binding instrument to address issues of air pollution on a broad regional basis and, notably, created an institutional framework for integrating research and policy. Annex VI, the most recent substantial amendment to the International Convention for the Prevention of Pollution from Ships (MARPOL 1973/1978; Annex VI entered into force 19 May 2005), regulates emissions of air pollution from ships. Many parallels exist between air pollution and noise in the ocean; for instance, sound from seismic surveys, similar to atmospheric emissions from ships, may travel thousands of kilometers from its source. The precedential authority of an air pollution convention is strengthened because the EU and various international authorities, such as the Convention on Biological Diversity and Convention on Migratory Species, now classify ocean noise as a pollutant. Furthermore, the International Organization for Standardization (ISO 2012, 2014) and the International Maritime Organization (IMO; IMO 2014) have produced guidelines to, respectively, measure and reduce underwater noise from commercial vessels.

There are several options for creating new and legally binding commitments to control sources of noise in the oceans. First, member states of the IMO could pursue an annex to MARPOL 1973/1978 through the Marine Environmental Protection Committee. This approach is attractive because it leverages an existing and effective framework, and could include radiated underwater noise from vessel operation along with geophysical survey noise. But it is not without challenges. Provisions within MARPOL that cover underwater noise would have to amend the Convention's definition of "harmful substances", which currently does not capture energy or 
sound, and perhaps revise the definition of "discharge", which presently omits the release of harmful substances associated with offshore mineral development (although oil and gas do not have the physical properties of "minerals", they are included as such in the legal regimes governing the seabed in Part XI and the resources of the continental shelf in Part VI of the Law of the Sea Convention, and would also have to be considered). MARPOL applies solely to "ships", however, and some might suggest that the term's definition, while broad, excludes towed airgun arrays. But these issues present only semantic obstacles, which can be overcome if states are committed to the regulation of noise. As an alternative, states could negotiate a brand new convention to regulate all non-military sources of underwater noise, including those emanating from industrial, geophysical, and civilian vessel sources. The process for negotiation of such an instrument is lengthy but the obstacles would not be insurmountable. Building on previous ideas for sustainable governance of ocean issues (Costanza et al. 1998) and integrated ocean management (Foley et al. 2013), we propose that a convention on ocean noise could draw upon leading analytical frameworks of decision-making behavior in the context of policy and governance processes of change (eg the Institutional Analysis and Development [IAD] Framework [McGinnis 2011] or the social-ecological system framework [Ostrom 2009; Basurto and Nenadovic 2012]). Within one of these frameworks, different scenarios for sustainable planning can be explored. Scenario planning has been used extensively in the commercial sector, is a well-developed tool in business planning (Schoemaker 1995), and is emerging as an essential element in studies of the environment (Peterson et al. 2003a, b) and global change (Bennett et al. 2003). Importantly, an accepted international convention would facilitate long-range planning in the use of acoustic sources.

We suggest the following as an initial list of measures to be included in a new convention:

\section{(1) Empirically based restrictions on the time, duration, and/or area of activities in known biologically important habitats}

Many habitats could be included in this measure, such as bowhead whale (Balaena mysticetus) feeding areas in the Beaufort and Chukchi Seas; feeding areas, calving areas, and migration routes for North Atlantic right whales (Eubalaena glacialis); areas in the North Sea inhabited by acoustically sensitive harbor porpoises (Phocoena phocoena) and fish; blue whale (Balaenoptera musculus) habitat south of Australia; and important sperm whale (Physeter macrocephalus) and Bryde's whale (Balaenoptera brydei) habitats in the Gulf of Mexico. Understanding marine species' habitat requirements throughout their entire annual cycle in any particular region - relative to the occurrence of seismic surveys conducted therein - is essential. Such biologically important habitats could be proposed as marine pro- tected areas (MPAs), or, in keeping with the proposal to rely on existing international instruments used by the IMO, they could be designated as areas to be avoided (ATBAs) or as particularly sensitive sea areas (PSSAs). The effectiveness of MPAs, ATBAs, or PSSAs could be minimal, however, given the distances that ocean noise including seismic survey signals - can travel underwater. Time and/or area restrictions are often a risk-assessment calculation and represent trade-offs. Time-sharing may be impossible when, for example, the waters are available to animals and surveys for only short windows due to the presence of ice (eg Nowacek et al. 2013).

\section{(2) Requirements for sustained monitoring of acoustic habitat indicators (eg spatial, seasonal ambient noise levels across species-specific frequencies), with limitations and targets based on the cumulative noise contributions of human activities}

Such an approach is consistent with the Marine Strategy Framework Directive currently being implemented in the EU (EU 2008). Monitoring should include data-gathering efforts that improve baseline knowledge about species of concern. This objective can be achieved in part by systematically integrating passive listening capabilities into ocean-observing systems. While most governments have been slow to implement such practices (Southall et al. 2012), some examples exist, such as the Australian Ocean Data Network Portal (http://portal.aodn.org. au/aodn).

\section{(3) Preconditions to develop and implement practices that reduce the acoustic footprint of seismic surveys and other activities}

Any new convention should encourage the development of less invasive exploration techniques, such as vibroseis (a vibratory source that emits more continuous energy, lower in peak energy than airguns and narrower in frequency), which has been used successfully in terrestrial applications for geophysical exploration (Echtler et al. 1996) and shows promise in the marine environment (Weilgart 2010). Methods to minimize exploration impacts should also include data-sharing requirements or other reasonable arrangements to help reduce or eliminate duplicative surveys.

\section{(4) Creation of an intergovernmental science organization that can coordinate and advance efforts to improve the environmental assessment of acoustic impacts}

Such efforts should include the development and application of metrics for assessing the health of potentially affected organisms and populations, such as quantitative assessments of vital rates, prey availability, ranging pat- 
terns, and body condition (eg population consequences of acoustic disturbance [PCAD] or simply "of disturbance" [PCoD]; Harwood et al. 2011).

\section{(5) Requirements for the preparation of EIAs and strategic or programmatic environmental assessments that analyze the potential for cumulative effects}

Regulators must explicitly assess and manage the risks of additive and synergistic acoustic exposures, which have demonstrated detrimental effects on humans and other mammals (Warner and Heimstra 1971; Evans 2003; Otten et al. 2004; Wright et al. 2007). Recently developed tools that map human noise and cetacean densities can be used for assessing acoustic impact, cumulative and otherwise (NOAA 2012).

In the absence of an international convention, existing regional authorities may be amenable to incorporating regulation of underwater noise in their regimes. In Europe, ocean noise has occupied the work plans of several regional accords (eg the Agreement on the Conservation of Cetaceans in the Black Sea, Mediterranean Sea and Contiguous Atlantic Area and the Agreement on the Conservation of Small Cetaceans of the Baltic and North Seas, sub-agreements of the Convention on Migratory Species that address cetacean conservation in the Mediterranean, Black, Baltic, and North Seas) for more than a decade, resulting in the first regional noise guidelines (ACCOBAMS 2010), which include seismic exploration. Multinational instruments in other parts of the world that regulate regional seas, such as the Abidjan Convention (UNEP 1984) and the Lima Convention (UNEP 1986), include ocean noise within their "competence" (a term with precise legal implications). Actions taken by these authorities generally constitute "soft laws", however, which are useful for facilitating regional cooperation and coordination but are not strictly binding for member states and therefore cannot substitute for an international convention. Creating a pan-Arctic plan, given the pace of development and rapid environmental change occurring in the region, is an urgent matter. The intergovernmental Arctic Council (www.arctic-council.org) would be a natural partner in this regard, and could serve as a vehicle for a binding regional treaty.

Elected officials, business leaders, and members of the public, by pressuring governments and industries, possess the influence necessary to encourage sectors engaged in ocean-based commerce to address marine noise. The actions of socially responsible investors and progressive policies put forth by the regulatory community can play a large role in this process. In the near term, indicators of stewardship - such as certification of "ocean friendly" technologies and organizational strategies to limit anthropogenic noise and rates of exposure - should be incorporated by firms engaged in marine resource explo- ration and extraction, as well as by transboundary cargoshipping firms. Secondly, a parallel path should be created to incorporate anthropogenic noise into life-cycle ("cradle to grave") inventory analysis for commercial products (eg Guinee 2002), thus serving as a catalyst for industry to work with researchers in developing more robust spatial and temporal datasets to better quantify the risks and impacts of marine seismic activities and improve the effectiveness of intervention strategies.

At the national level, regulatory engagement can play a critical role in driving innovation. For example, in 2011, the German government issued an action-forcing standard for noise caused by pile-driving activity, requiring operators to reduce pressure levels below a given threshold within a defined radius of the source (Umweltbundesamt 2011). After allowing the industry time to develop technology and methods of compliance, the government now includes the standard in licenses for offshore windfarm construction. Regulators should use analogous mechanisms and other prescriptive and incentive-based tools to promote noise reduction in the seismic exploration industry, which - despite a long-recognized need - has been slow to develop noise-control technologies and alternative technologies and bring them into commercial use. Marine sustainability should be considered as a race to the top, not as a scramble to keep from being the worst.

Ultimately, if we are to understand, control, and reverse the chronic deterioration of marine acoustic environments and its expected impacts on marine ecosystems over the coming decades, regulators should begin establishing cumulative-exposure limits for anthropogenic noise. These limits should be appropriately matched to the spatiotemporal scale and exposure rate of the risks to individuals and populations. The lack of baseline data should not be construed as free rein to proceed unchecked until negative effects are demonstrated. Both public and private institutions have the opportunity to correct our current path and to ensure the resilience and health of marine ecosystems.

\section{Acknowledgements}

We thank RR Reeves and AJ Read for comments on previous versions of this manuscript, and LM Campbell and $\mathrm{X}$ Basurto for comments on the way forward we have proposed.

\section{References}

ACCOBAMS (Agreement on the Conservation of Cetaceans of the Black Sea, Mediterranean Sea and contiguous Atlantic area). 2010. Guidelines to address the impact of anthropogenic noise on cetaceans in the ACCOBAMS area. ACCOBAMS resolution 4.17. Monaco, Principality of Monaco: ACCOBAMS.

Basurto X and Nenadovic M. 2012. A systematic approach to studying fisheries governance. Global Policy 3: 222-30.

Bejder L, Samuels A, Whitehead H, et al. 2009. Impact assessment 
research: use and misuse of habituation, sensitisation and tolerance in describing wildlife responses to anthropogenic stimuli. Mar Ecol-Prog Ser 395: 177-85.

Bennett E, Carpenter S, Peterson G, et al. 2003. Why global scenarios need ecology. Front Ecol Environ 1: 322-29.

Blackwell SB, Nations CS, McDonald TL, et al. 2013. Effects of airgun sounds on bowhead whale calling rates in the Alaskan Beaufort Sea. Mar Mammal Sci 29: E342-E365.

BOEM (Bureau of Ocean Energy Management). 2014a. Quieting technologies for reducing noise during seismic surveying and pile driving workshop: summary report. OCS Report BOEM 2014-061. Herndon, VA: BOEM.

BOEM (Bureau of Ocean Energy Management). 2014b. Atlantic OCS proposed geological and geophysical activities, MidAtlantic and South Atlantic planning areas, final programmatic environmental impact statement. OCS EIS/EA BOEM 2014-001. Herndon, VA: BOEM.

Castellote M, Clark CW, and Lammers MO. 2012. Acoustic and behavioural changes by fin whales (Balaenoptera physalus) in response to shipping and airgun noise. Biol Conserv 147: $115-22$.

Cato DH, Noad MJ, Dunlop RA, et al. 2011. Behavioral response of Australian humpback whales to seismic surveys. J Acoust Soc Am 129: 2936.

CBD (Convention on Biological Diversity). 1992. 5 Jun 1992, 1760 UNTS 79; 31 ILM 818. Entered into force 29 Dec 1992. New York, NY: UN.

Cerchio S, Strindberg S, Collins T, et al. 2014. Seismic surveys negatively affect humpback whale singing activity off northern Angola. PLoS ONE 9: e86464.

Clark CW and Ellison WT. 2004. Potential use of low-frequency sounds by baleen whales for probing the environment: evidence from models and empirical measurements. In: Thomas J, Moss C, and Vater M (Eds). Echolocation in bats and dolphins. Chicago, IL: The University of Chicago Press.

Clark CW, Ellison WT, Southall BL, et al. 2009. Acoustic masking in marine ecosystems: intuitions, analysis, and implication. Mar Ecol-Prog Ser 395: 201-22.

CLRTAP (Convention on Long-range Transboundary Air Pollution). 1979. 1302 UNTS 217; 18 ILM 1442. Entered into force 16 Mar 1983. Geneva, Switzerland: UN Economic Commission for Europe.

Costanza R, Andrade F, Antunes P, et al. 1998. Principles for sustainable governance of the oceans. Science 281: 198-99.

CPD (Cartagena Protocol on Biosafety). 2000. 2226 UNTS 208; 39 ILM 1027; UN Doc. UNEP/CBD/ExCOP/1/3, at 42. Entered into force 11 Sep 2003. Montreal, Canada: Secretariat of the Convention on Biological Diversity.

Echtler HP, Stiller M, Steinhoff F, et al. 1996. Preserved collisional crustal structure of the southern Urals revealed by vibroseis profiling. Science 274: 224-26.

EU (European Union). 2008. Marine strategy framework directive. Directive 2008/56/EC, 17 Jun 2008, Official Journal of the European Union, L 164/19, 25 Jun 2008, part 3(8). Brussels, Belgium: EU.

EU (European Union). 2014. Directive of the European Parliament and of the Council amending Directive 2011/92/EU on the assessment of the effects of certain public and private projects on the environment, 2012/0297 (COD), PE-CONS 15/14, 19 Mar 2014. Brussels, Belgium: EU.

Evans GW. 2003. A multimethodological analysis of cumulative risk and allostatic load among rural children. Dev Psychol 39: 924-33.

Foley MM, Armsby MH, Prahler EE, et al. 2013. Improving ocean management through the use of ecological principles and integrated ecosystem assessments. BioScience 63: 619-31.

Grebmeier JM, Overland JE, Moore SE, et al. 2006. A major ecosystem shift in the northern Bering Sea. Science 311: 1461-64.

Guerra M, Thode AM, Blackwell SB, and Macrander AM. 2011.
Quantifying seismic survey reverberation off the Alaskan North Slope. J Acoust Soc Am 130: 3046-58.

Guinee JB. 2002. Handbook on life cycle assessment: operational guide to the ISO standards. Dordrecht, the Netherlands: Springer.

Harwood J, Costa DP, Tyack PL, and Weise M. 2011. A conceptual framework for evaluating the effects of sound on marine mammals. 96th Meeting of the Ecological Society of America; 7-12 Aug 2011; Austin, TX.

Hatch LT, Clark CW, Van Parijs SM, et al. 2012. Quantifying loss of acoustic communication space for right whales in and around a US national marine sanctuary. Conserv Biol 26: 983-94.

HESS (High Energy Seismic Survey) Team. 1999. High energy seismic survey review process and interim operational guidelines for marine surveys offshore southern California. Camarillo, CA: California State Lands Commission and US Minerals Management Service.

Hildebrand JA. 2009. Anthropogenic and natural sources of ambient noise in the ocean. Mar Ecol-Prog Ser 395: 5-20.

IMO (International Maritime Organization). 2014. Noise from commercial shipping and its adverse impacts on marine life. London, UK: IMO. MEPC 66/17.

ISO (International Organization for Standardization). 2012. Acoustics - quantities and procedures for description and measurement of underwater sound from ships design considerations. Geneva, Switzerland: ISO. ISO/PAS 17208-1.

ISO (International Organization for Standardization). 2014. Ship and marine technology - measurement and reporting of underwater sound radiated from merchant ships - deep-water measurement. Geneva, Switzerland: ISO. ISO/DIS 16554

Jochens A, Biggs D, Benoit-Bird K, et al. 2008. Sperm whale seismic study in the Gulf of Mexico: synthesis report. New Orleans, LA: US Department of the Interior, Minerals Management Service, Gulf of Mexico OCS Region.

MARPOL (International Convention for the Prevention of Pollution from Ships). 1973/1978. 2 Nov 1973, 1340 UNTS 184; 12 ILM 1319. Entered into force 2 Oct 1983. London, UK: IMO.

McCauley RD, Fewtrell J, and Popper AN. 2003. High intensity anthropogenic sound damages fish ears. J Acoust Soc Am 113: $638-42$.

McGinnis MD. 2011. An introduction to IAD and the language of the Ostrom Workshop: a simple guide to a complex framework. Policy Stud J 39: 169-83.

Miller GW. 2005. Monitoring seismic effects on marine mammals southeastern Beaufort Sea, 2001-2002. In: Armsworthy SL, Cranford PJ, and Lee K (Eds). Offshore oil and gas environmental effects: monitoring, approaches and technologies. Columbus, $\mathrm{OH}$ : Battelle Press.

Miller PJO, Johnson MP, Madsen PT, et al. 2009. Using at-sea experiments to study the effects of airguns on the foraging behavior of sperm whales in the Gulf of Mexico. Deep-Sea Res Pt I 56: 1168-81.

National Marine Fisheries Service (NMFS). 2013. Effects of oil and gas activities in the Arctic Ocean: supplemental draft Environmental Impact Statement. Prepared by NMFS, Office of Protected Resources. www.nmfs.noaa.gov/pr/permits/eis/arctic_sdeis.pdf. Viewed 4 Aug 2015.

Nieukirk SL, Stafford KM, Mellinger DK, et al. 2004. Low-frequency whale and seismic airgun sounds recorded in the mid Atlantic Ocean. J Acoust Soc Am 115: 1832-43.

Nieukirk SL, Mellinger DK, Moore SE, et al. 2012. Sounds from airguns and fin whales recorded in the mid-Atlantic Ocean, 1999-2009. J Acoust Soc Am 131: 1102-12.

NOAA (National Oceanic and Atmospheric Administration). 2012. Mapping cetaceans and sound: modern tools for ocean management. Bethesda, MD: NOAA.

Nowacek D, Bröker K, Donovan GP, et al. 2013. Responsible prac- 
tices for minimizing and monitoring environmental impacts of marine seismic surveys with an emphasis on marine mammals. Aquatic Mammals 39: 356-77.

Ostrom E. 2009. A general framework for analyzing sustainability of social-ecological systems. Science 325: 419-22.

Otten W, Kanitz E, Puppe B, et al. 2004. Acute and long term effects of chronic intermittent noise stress on hypothalamic-pituitary-adrenocortical and sympathoadrenomedullary axis in pigs. Anim Sci 78: 271-83.

Peterson G, Beard Jr T, Beisner B, et al. 2003a. Assessing future ecosystem services: a case study of the Northern Highlands Lake District, Wisconsin. Conserv Ecol 7: 1.

Peterson G, Cumming G, and Carpenter S. 2003b. Scenario planning: a tool for conservation in an uncertain world. Conserv Biol 17: 358-66.

Pirotta E, Brookes KL, Graham IM, and Thompson PM. 2014. Variation in harbour porpoise activity in response to seismic survey noise. Biol Lett 10: 20131090.

Richardson W, Miller G, and Greene CJ. 1999. Displacement of migrating bowhead whales by sounds from seismic surveys in shallow waters of the Beaufort Sea. J Acoust Soc Am 106: 2281.

Rio Declaration. 1992. Rio Declaration on Environment and Development, 13 Jun 1992, UN Doc A/CONF.151/26 (v I); 31 ILM 874 (1992) (Principle 15). New York, NY: UN.

Robertson FC, Koski WR, Thomas TA, et al. 2013. Seismic operations have variable effects on dive-cycle behavior of bowhead whales in the Beaufort Sea. Endangered Species Research 21: $143-60$.

Rosenbaum HC, Maxwell SM, Kershaw F, and Mate B. 2014. Long-range movement of humpback whales and their overlap with anthropogenic activity in the South Atlantic Ocean. Conserv Biol 28: 604-15.

Schoemaker P. 1995. Scenario planning: a tool for strategic thinking. Sloan Manage Rev 36: 25-40.

Slotte A, Hansen K, Dalen J, and Ona E. 2004. Acoustic mapping of pelagic fish distribution and abundance in relation to a seismic shooting area off the Norwegian west coast. Fish Res 67: 143-50.

Southall BL, Dushaw B, Moore SE, et al. 2012. Ocean acoustic monitoring in IOOS: tools for measuring natural systems and human impacts. IOOS Summit 2012: a new decade for an integrated and sustained ocean observing system; 13-16 Nov 2012; Herndon, VA. Washington, DC: IOOC.

Southall BL, Rowles T, Gulland F, et al. 2013. Final report of the Independent Scientific Review Panel investigating potential contributing factors to a 2008 mass stranding of melon-headed whales (Peponocephala electra) in Antsohihy, Madagascar. Cambridge, UK: International Whaling Commission.

Taylor BL, Martinez M, Gerrodette T, and Barlow J. 2007. Lessons from monitoring trends in abundance of marine mammals. Mar Mammal Sci 23: 157-75.
Thompson PM, Brookes KL, Graham IM, et al. 2013. Short-term disturbance by a commercial two-dimensional seismic survey does not lead to long-term displacement of harbour porpoises. P R Soc B 280: 20132001.

Umweltbundesamt. 2011. Empfehlung von Lärmschutzwerten bei der Errichtung von Offshore-Windenergieanlagen (OWEA). Dessau, Germany: Umweltbundesamt.

UNCLOS (United Nations Convention on the Law of the Sea). 1982. 10 Dec 1982, 1833 UNTS 397; 21 ILM 1261. Entered into force 16 Nov 1994. New York, NY: UN.

UNEP (United Nations Environment Programme). Convention for Co-operation in the Protection and Development of the Marine and Coastal Environment of the West and Central African Region and Protocol. Entry into force 5 Aug 1984. Nairobi, Kenya: UNEP.

UNEP (United Nations Environment Programme). 1986. Convention for the Protection of the Marine Environment and Coastal Areas of the South-East Pacific. Entry into force 1986 (day and month unknown). Nairobi, Kenya: UNEP.

UNSCBD (United Nations Secretariat of the Convention on Biological Diversity). 2000. Cartagena Protocol on Biosafety to the Convention on Biological Diversity: text and annexes. Montreal, Canada: Secretariat of the Convention on Biological Diversity.

Urick RJ. 1983. Principles of underwater sound. Los Altos, CA: Peninsula Publishing.

Wardle CS, Carter TJ, Urquhart GG, et al. 2001. Effects of seismic air guns on marine fish. Cont Shelf Res 21: 1005-27.

Warner HD and Heimstra NW. 1971. Effects of intermittent noise on visual search tasks of varying complexity. Percept Motor Skill 32: 219-26.

Weilgart LS (Ed). 2010. Report of the workshop on Alternative Technologies to Seismic Airgun Surveys for Oil and Gas Exploration and their Potential for Reducing Impacts on Marine Mammals. Darmstadt, Germany: Okeanos Foundation for the Sea. www.okeanos-foundation.org/assets/ Uploads/Airgun.pdf. Viewed 1 Jun 2015.

Wright AJ, Soto NA, Baldwin AL, et al. 2007. Anthropogenic noise as a stressor in animals: a multidisciplinary perspective. Int J Comp Psychol 20: 250-73.

${ }^{5}$ School of Biology, University of St Andrews, St Andrews, UK; ${ }^{6}$ Ocean Giants Program, Wildlife Conservation Society, New York, NY; ${ }^{7}$ Nicholas School of the Environment, Division of Earth $\mathbb{6}$ Ocean Sciences, Duke Center for Sustainability $\mathcal{E}$ Commerce, Duke University, Durham, NC; ${ }^{8}$ Natural Resources Defense Council, Santa Monica, CA; ${ }^{9}$ Southall Environmental Associates and University of California, Santa Cruz, Santa Cruz, CA 